University of Massachusetts Amherst

ScholarWorks@UMass Amherst

Communication Department Faculty Publication

Series

Communication

2020

\title{
What smartness does in the smart city: From visions to policy
}

Burcu Baykurt

University of Massachusetts Amherst

Christoph Raetzsch

Aarhus University

Follow this and additional works at: https://scholarworks.umass.edu/communication_faculty_pubs

\section{Recommended Citation}

Baykurt, Burcu and Raetzsch, Christoph, "What smartness does in the smart city: From visions to policy" (2020). Convergence: The International Journal of Research into New Media Technologies. 111.

https://doi.org/10.11771354856520913405

This Article is brought to you for free and open access by the Communication at ScholarWorks@UMass Amherst. It has been accepted for inclusion in Communication Department Faculty Publication Series by an authorized administrator of ScholarWorks@UMass Amherst. For more information, please contact scholarworks@library.umass.edu. 


\title{
What Smartness Does in the Smart City: From Visions to Policy
}

\begin{abstract}
This article examines what smartness does on the ground by examining how its anticipatory media visions have been interpreted and acted on in policy decisions and local implementations since the early 2000s. Using a comparativehistorical analysis that draws on fieldwork in aspiring smart cities in the United States and Europe, we argue that the visions of smartness are neither singular nor fixed across time and space. Instead, the role of smartness in diffusing new technologies is recruited and reshaped in the present to lend legitimacy to future public and private interventions. We first demonstrate that the narrative of crisis, often associated with smartness, shifted from a pre-2008 emphasis on sustainability and climate change to a post-financial crisis engagement with entrepreneurship and platformization. We then discuss how the development of smart city initiatives has followed divergent paths in the United States and Europe, with big tech companies dominating in the former and the 'living lab' model prevailing in the latter. Our analysis highlights the importance of investigating the complex relationships between anticipatory media visions of smartness and their varying, down-to-earth implementations in the built environment rather than solely focusing on the discursive appeal of technoidealism. It also explains the enduring appeal of smartness as an urban vision, despite its various shortcomings, by revealing its adaptability to the changing social and political-economic shifts.
\end{abstract}

\section{Introduction}

Over the past decade, the smart city has emerged as a space in which anticipations and calculations about societal futures are constructed in the present (Albino et al., 2015; Cocchia and Dameri, 2016; Halpern et al., 2017). The growing scholarship in this area has demonstrated that smartness, as a particular urban vision, emboldens the kind of technological idealism that promotes efficiency and innovation across urban spaces (Hollands, 2015). Policymakers also believe that smartness can be a pathway to 'more interactive and responsive city administration' (European Commission, 2018). Well-established critiques of the smart city take issue with these socio-technical imaginaries, which falsely 
amplify local challenges to justify media technologies as the only viable solution (de Waal et al., 2017; Green, 2019; Greenfield, 2013; Mattern, 2017a). Urban issues are too complicated to be solely managed by technological affordances, which are already embedded in the dominant structures of power and politics. The vision of an integrated urban dashboard that monitors local operations in real time may understandably appeal to overworked public officials, but the record of cybernetic attempts at urban control since the 20th century is at best ineffectual (Light, 2003; Mattern, 2013; Vallianatos, 2015). Moreover, the current incarnations of data-powered visions of local governance still leave a lot to be desired when it comes to how they conceive of the city as a site of everyday democracy (Araya, 2015; Burdett, 2013; Graham, 2018).

Yet smartness remains a powerful vision pervading hundreds of urban centers around the world. Its claims and promises may be exaggerated, nonetheless its future-minded hyperbole is persuasive enough to prompt significant material and symbolic investments across cities. Funds are reshuffled, regulations are adjusted, new collaborations are initiated among different groups, new infrastructural projects are implemented. As public officials and local entrepreneurs take up the logics and practices of smartness, they even reshape the layout of cities, demarcating some neighborhoods as innovation districts or smart city test beds.

Rather than taking these visions of the smart city at face value, this article addresses what smartness does on the ground by examining how these visions are interpreted and acted on in policy decisions and local implementations. We 
pursue a comparative-historical approach and draw on fieldwork in aspiring smart cities as well as analyses of corporate and policy documents in the United States and Europe. We suggest that actors at the core of the smart city - public officials, tech companies, and engaged residents - justify and mobilize smartness not just as a remarkable fantasy but also as a pragmatic response to immediate problems. Contrary to conventional framings that position smartness as rational, universal, and predominantly market-driven, our interlocutors understand it as a possible solution to the everyday failings of urban infrastructures as well as an opportunity to generate collaborations across various stakeholders. Smartness becomes embedded in practical responses to shifting structural conditions of managing cities rather than purely celebrating technologies for their own sake or solely projecting futuristic assertions.

As Jathan Sadowski and Roy Bendor (2019) argue, smartness in an urban context typically starts from a language of crisis wherein the anticipation of a dystopian future warrants preemptive preparation in the present, enabled by technological capabilities of real-time sensing and data processing. Yet this crisis narrative is neither singular nor fixed across time and space. We argue that the role of smartness in diffusing new technologies is recruited and reshaped in the present to lend legitimacy to various public and private interventions on behalf of perceived future needs. We first demonstrate how the narrative of crisis shifted from a pre-2008 emphasis on sustainability and climate change to a postfinancial crisis engagement with entrepreneurship, innovation, and the building of 'regional innovation ecosystems' (Committee of the Regions, 2016). We then 
discuss how the development of smart city initiatives has followed divergent paths in the United States and Europe, with big tech companies dominating in the former and the 'living lab' model prevailing in the latter.

These two comparative dimensions (one operating across time, the other across geography) allow us to establish that the visions of smartness are flexible means to pursue stability in unstable times. We thus challenge the views that the utopian and dystopian visions of the smart city are accepted by local governments because of a blind faith in techno-determinism or complete reliance on urban entrepreneurialism (Harvey, 1989). Instead smartness, as a set of technologies, new sources of funding, and a branding strategy, helps local governments articulate pragmatic solutions in the immediate present to structurally thorny urban problems. Many public officials turn to smart technologies to funnel attention and funds to repair flailing urban systems in the absence of public funding and political action. Our argument does not reject the very well-established critiques of the smart city, which have effectively showcased how corporate visions of smartness are mere attempts to sell surveillance technologies and data analytics to local governments. We also do not argue that smart technologies are indeed the solutions that they profess to be. On the contrary, our research projects in US and European cities have so far concluded that these new systems have a long way to go to deliver the results they have promised to espouse (Baykurt, 2019). Despite these shortcomings, our contribution reveals why the visions of smartness remain appealing to cities by 
identifying their adaptability to the changing social and political-economic shifts on the ground.

In the following pages, we first present a brief overview of what kind of urban visions undergird smartness and how urban temporalities mediate its socio-technical imaginaries. We then revisit the recent history of how US-origin tech companies have interpreted smartness, and contrast this with living lab methodologies present across the European Union (EU) to discuss how visions of smartness have shifted and how smartness is operationalized differently. We conclude the article by examining the relationships between anticipatory media visions of the smart city and the varying, down-to-earth implementations in the built environment.

\section{Temporalities of Smartness: Between Crisis and Utopia}

Even though smart cities are all the rage these days, they still lack a clear definition. Based on a comprehensive analysis of corporate and academic documents on the subject, the Focus Group in Smart Sustainable Cities of the International Telecommunications Union (ITU) found more than a hundred definitions of what 'smart city' can mean (ITU-T Focus Group on Smart Sustainable Cities, 2014). A similar study concluded that smart cities ‘lack universality' as each city launches smartness with different visions or objectives (Albino et al., 2015: 18). Along with alternate descriptors, such as 'intelligent' or 'responsive' cities, smart cities represent shifting assumptions about the relationship between urban environments and technology, especially by 
anticipating 'post-anthropocentric cities of tomorrow' (Yigitcanlar et al., 2017: 150).

Despite the lack of precision in definitions, smartness in public imagination usually conjures up a networked environment that can automate and respond to everyday human behavior. Think about your Wi-Fi-connected smart phone, houses, and, of course, streets. Yet, as Halpern et al. (2017) explain, the appeal of smartness lies not only in its infrastructural capacity via computing but also in 'an orienting telos about what smartness is and does' (p. 108). Recognizing a decisive break from the Cold War notions of centralized control, the authors suggest smartness offers 'neither reason nor rationality' (Halpern et al., 2017: 110), as it elevates resilience and optimization above all else. By constantly experimenting with data models and real-time information, smartness envisions sustainability as the outcome of the continual testing and tweaking of data analysis in city spaces. In other words, the world-making power of smartness is derived from a remarkable presence on the ground in the form of wires, sensors, cameras, and dashboards that promise to capture everyday life in granular detail, and what people can potentially do with that data to solve urban problems.

The socio-technical imaginary of the smart city is not limited to mere techno-utopianism but also depends on a 'language of crisis' (Halpern et al, 2017: 108). Corporate documents by the leaders in the smart city market, IBM and Cisco, perennially follow the same narrative: '[S] toke a crisis (or three), theorize a framework for transforming the city, marshal solutions to fix what ails city 
clients, and strategize about different implementation styles' (Sadowski and Bendor, 2019: 556). The technical capabilities of smart technologies are important to make a case for their adoption in a city. But it is the intentionally magnified complexity of local problems that ostensibly makes smartness essential. For the municipalities that have to deal with too many local challenges at the same time, the promise of smartness to solve many problems at once is alluring. Similarly appealing are the dashboards that seem to integrate the disjointed fragments of local services, as public officials need to respond to demands for efficient service delivery with shrinking public resources.

We suggest that the utopian and dystopian visions of the smart city - or what Sadowski and Bendor (2019) call the 'visionary and reactionary' elements of smartness - are mediated by a variety of temporalities. For one, smart technologies are branded as a convincing way to bring the future into the present city. Potential scenarios of complex urban problems along with pressing yearnings for social change become mechanisms to manage the future and present claims of smart technologies. Municipalities and tech companies draw on some of the immediate urban issues, such as decaying water pipes, an urgent traffic management problem, or even an upcoming request for (procurement) proposal, as opportunities to test future technologies. They also invoke prospective concerns with climate change, energy scarcity, security, and economic decline to legitimize smart technologies even when their impact for justice and equity is dismal at the moment (Goodman and Powles, 2019). 
These various temporalities of smartness are not solely discursive; they are also dependent on a whole stack of material infrastructures, such as pipes, cables, data centers, and urban dashboards (Graham, 2018). Cities embed various data collection devices across urban centers to assess the likelihood of future behaviors or events. This 'anticipatory governance' model focuses on the future while extensively using past and real-time data (Kitchin, 2014). In addition to acting on intelligence from past and present data collection, the smart city also tries to manage its everyday life. As much as it is about anticipating futures, the 'real-time city' is also about keeping the pulse of urban life through live feeds of '...road traffic sensors, pollution monitors, flood sensors [that] are appropriated within a very immediate time-frame to manage the here-and-now' (Leszczynski, 2016: 1693). It is usually in the mixing of statistical models with messy real-time and past data that we most clearly see the disjunct temporalities of smartness and the limits of what it can and cannot do. In other words, smartness does not just oscillate between dystopian and utopian visions; it simultaneously moves between the past, present, and the future to legitimize itself and make smart technologies look useful to policymakers, researchers, and citizens.

By inquiring into what smartness does in the city, we aim to demonstrate how these conflicting narratives and disjointed temporalities mobilize divergent resources in the present and legitimate (or delegitimate) certain local problems in the future. We trace these shifts both across time and space to comparatively analyze the diverse premises and promises of smartness. We thus challenge the assumption that the persuasive capacity of smartness depends solely on its 
discourses and imaginaries. Pragmatic considerations and collaborations (Cocchia and Dameri, 2016) are equally important in stabilizing the overwhelming appeal of smartness. Our approach allows to examine how visions are operationalized in response to actual, day-to-day problems and demonstrate how seemingly universal trajectories of futures are animated within varying cultural, social, and political conditions. The point is neither to follow nor debunk a particular vision of the future in which media technologies play a central role. We aim to show that the negotiation around central tenets of future visions reveals both diverse assessments of current state of affairs and the complex relationship between media technologies and their future-making capacity.

\section{From Climate Change to Urban Platforms: Smartness as Permanently Beta}

Despite the tech industry's repeated hype about algorithms, artificial intelligence, and machine learning, the early visions about the smart city were focused on something different: climate change. No company was politically bold enough to spell it out explicitly, but energy scarcity and sustainability were at the center of both Cisco and IBM's initial propositions about smart cities in the early 2000s. In 2006, former US President Bill Clinton, through the Clinton Foundation's global initiative, asked Cisco to act on climate change. That is how Cisco committed the first 15 million US dollars to launching the Connected Urban Development (CUD) program, which later became the backbone of its smart cities initiatives. CUD originally aimed to increase the efficiency of traffic flow via new 
technologies, thereby reducing carbon emissions. It was launched in a number of global cities, including San Francisco, Seoul, Amsterdam, Madrid, and Hamburg. Hoping to model cities after the so-called infrastructural efficiency of the Internet at the time, Cisco declared, 'Our fundamental belief is that today's flow of people, goods, energy, information, media, and services in cities can be as efficient as the traffic of digital packets on the internet' (Villa and Mitchell, 2009: 6).

IBM's foray into smart cities was no different. The company's then president and CEO Samuel Palmisano announced their vision for a 'Smarter Planet' in a speech to the Council on Foreign Relations in 2008. Peddling a similar crisis narrative for cities that were facing 'a range of challenges and threats to their sustainability across all their core systems that they need to address holistically', IBM's program suggested that a smart city 'uses technology to transform its core systems and optimize the return from largely finite resources' (Dirks and Keeling, 2009). Again, there was no explicit reference to climate change, but there was a nod to 'a crisis of global scale' (Sadowski and Bendor, 2019: 550) and a planetary vision for smartness from the outset.

These leading companies in the smart city market started shifting their narratives and organizational structures around 2009. In February 2009, Cisco declared that the CUD program was evolving into a 'Smart and Connected Communities' $(\mathrm{S}+\mathrm{CC})$ initiative'. Much bolder than simply providing efficiency, Cisco's new program expanded to 'enable economic, social and environmental sustainability and transform communities, cities and countries' (Chakrabarti, 
2011). Then CEO of Cisco, John Chambers described this transformation for the company as 'mov[ing] from plumbing to being the platform for innovation' (Lindsay, 2010). Rather than merely selling hardware such as routers, Cisco was venturing into computing and data analytics to come up with innovative solutions for urban problems. Similarly, IBM acquired 25 analytics firms between 2008 and 2013 (McNeil, 2015). The company also launched a Smarter Cities Technology Center in Dublin in 2011 to 'solve problems such as pollution, resource inefficiencies, unreliability, crime, and social inequities' (IBM, 2011).

In just a few years, smartness, at least in corporate speak, shifted from a vision with a narrow focus on the efficiency-providing capabilities of technologies to one that emphasized innovation, community-building, and constant experimentation. These visions first became concrete in each company's attempt to institute smart cities outside the Unites States. On a landfill on the northwestern coast of South Korea, Cisco wired up the city of Songdo to prototype various urban technologies: video-conferences in all buildings, mobilephone-controlled residences, a customized public transit system, and a waste management system that eliminates trash cans on street corners (Halpern et al., 2013). IBM partnered with the city of Rio de Janeiro to open the Rio Operations Center in the end of 2010. The Center aimed to centralize urban management by integrating data from 30 different agencies and creating a monitoring system for public safety as well as other issues, such as traffic control, infrastructural maintenance, and emergency management (Gaffney and Robertson, 2018). ‘We don't have to wait for the resolution of ideological debates to make our city 
systems smarter', asserted IBM's then CEO Palmisano in 2011, 'if these city leaders share an ideology, it is this, "We believe in a smarter way to get things done"' (Palmisano, 2011). In these new versions of smartness, there was less emphasis on sustainability and energy savings, and more focus on retrofitting the urban environment, restructuring local governance, and promising innovation for cities.

The idealism of the so-called smart city, at least as articulated by tech companies, has transformed from a concern with climate change and sustainability to an aspiration toward a vaguer alternative, that is, innovation and experimentation. Especially in the immediate aftermath of the financial crisis of 2008/ 2009 (Sadowski, 2019; Tay, 2019; Townsend, 2013), this change of mind on the side of companies owes to the changing political economy of cities. With its combination of venture capital, technocratic governance, and seductive promise of innovation, smartness became music to the ears of local governments that were hit hard by austerity measures. As many cities grappled with the exodus of residents and businesses, local governments scrambled for alreadylimited resources. Meanwhile, decaying urban infrastructures increasingly became public concerns, and tech companies saw an opportunity to offer services in response to austerity. IBM was quite explicit about this strategy: '2008 ushered in a systemic and prolonged economic adjustment that has severely crippled the ability of governments to deliver expected services to citizens, let alone push for innovative, new services', the company proclaimed while introducing its data analytics as a solution (IBM, 2012 cited in Sadowski, 2019). Similarly, Cisco was 
publishing research papers which pointed out that ‘[F]ragilities in the global financial system threaten to stall, if not reverse, years of economic progress', and that smart technologies had the 'potential to rectify many of the challenges' (Evans, 2012). As Sadowski (2019) succinctly puts it, these companies, post-2008, exploited the austerity of many cities, particularly in the United States, to push smartness into urban environments.

Positioning themselves as advisers to local governments and offering techsavvy advice, corporations began to value, in both meanings of the word, decaying infrastructures, austere budgets, and discontented residents. Through public-private partnerships, they started taking stock of cities' problems, urban assets, and data inventories while connecting entrepreneurial groups with investors. At a time when local governments were adapting to a new level of 'doing more with less', the promise of smartness to generate efficiencies, attract capital, create new business, and become attractive for young, middle-class residents became wildly appealing. As new smart technologies were built into existing infrastructures of cities, public officials were also able to point to concrete changes in the urban environment as signs of improvement.

Around the same time, many tech companies and even municipal leaders also started articulating smartness as a way to think about cities as platforms. A platform, in broad strokes, refers to a flexible physical layer with adaptable software, which encouraged smart city enthusiasts to see city infrastructures in a new light. In July 2015, the Aspen Institute held a 2-day gathering with academics, policymakers, and tech executives to discuss this metaphor. 
Reporting on the meeting, Charles M Firestone of the Aspen Institute gave a lengthy description of what it means for cities to think and act like a platform: '...cities can leverage digital and network technologies, tapping the expertise of its many citizens and stakeholders, to work for solutions to urban problems, cocreate new activities, and engage citizens more directly in the city's work and play. They can use open data, crowdsourcing and urban prototyping to enhance both government services and enjoyment of local life in the city' (Bollier, 2016). The prevailing trend toward platformization in various areas of life (Goodman and Powles, 2019; Helmond, 2015; Nieborg and Poell, 2018; van Dijck et al., 2018) propelled not just municipalities but also local entrepreneurial communities and nonprofits to replicate what they perceive as an innovation strategy in urban environments.

For tech companies in the smart city market, a platform has become simultaneously an organizing metaphor and an actual infrastructure. Arvind Satyam, a managing director at Cisco, once suggested that it was important for cities to create an 'innovation platform', for example, which he described as a combination where 'large companies work with startups and local entrepreneurs as well as work with local government'. Cisco's product portfolio for cities also includes 'Kinetic', which the company describes as 'a single pane of glass [that] lets you view and manage data from the lighting, parking, traffic, waste management, and Wi-Fi deployments' in the city. Kinetic collects data from various city systems and devices, using wired and wireless connectivity. By transmitting data to the cloud and storing enormous amounts of information, 
Kinetic then renders urban intelligence available for analysis by other parties. Similar to what AirBnB suggests for housing or Uber/Lyft for transportation, companies such as Cisco or Alphabet's Sidewalk Labs increasingly offers 'platforms' - again as material systems as well as logics and visions - as a viable model to think about urbanism.

Rather than empty venerations of shiny new technologies or constant corporate propaganda, we thus suggest that smartness now runs apace in hundreds of cities because its vision ostensibly offers very explicit solutions to localities that were hit by austerity, and new tools that promise to collect data that might drive innovation. Tech companies position themselves as consultants, or partners even, to resource-poor municipalities while providing them with new technologies, data analytics, and, in some cases, capital investments. In addition to corporate funding, several federal grants during the Obama administration and incentives by the National League of Cities have opened up US cities to constant experimentation, entrepreneurial undertakings, and civic prototyping over the last decade. What started as technocratic steps toward sustainability in the early 2000s soon turned into an urban mode of 'permanently beta', wherein cities constantly collaborate with tech companies and tinker with digital technologies in search of innovation (Neff and Stark, 2004). Instead of tackling sustainability or climate change, smartness now legitimizes public and private interventions that prioritize data collection and optimization without any clearly defined expectations or mechanisms of accountability (Goodman and Powles, 2019). 


\section{Smartness through Living Labs}

While the vision of smartness shifted from sustainability to entrepreneurialism and innovation in the United States over the last decade, it has followed a highly different path in the fragmented political landscape of the EU. Rather than striving for a single smart city as a model, governments and actors in civil society as well as industry have gravitated toward working with several models of governance and multi-stakeholder engagement around smartness. This different approach is explained in part by the heterogenous political climate in the 28 member states of the EU where the roles and functions of new technologies need to be negotiated within multiple (and often conflicting) expectations, legal frameworks, levels of expertise, and financial backing. In contrast to industry-led initiatives to implement smartness in cities, the peculiar conditions in the EU require establishing common frameworks for all member states while including local expertise, winning industry support and observing broader policy objectives at the same time.

Another explanation for why smartness is interpreted in terms of a participatory, multi-stakeholder policy approach in Europe has to do with the long-term investment in social experiments with information technologies since the 1980s, especially in Scandinavian countries and the United Kingdom (ENoLL, 2016). The methodology of urban living labs emerged as a way to develop technology frameworks that started from a user-oriented perspective, building on concrete use cases and satisfying overlapping stakeholder demands. A living 
lab approach is typically defined as a user-focused design environment, a strategy of co-creation, and, increasingly, an institutionalized space wherein citizens, administrators, entrepreneurs, and academics come together to develop smartness into concrete applications (Karvonen and Heur, 2014). Practitioners of the living lab approach emphasize its core principles as fostering trust among different actors and focusing on user needs to better understand new technologies. Within the immediate local environment, living labs help identify and join localized expertise, real-life testing and prototyping with strategic networking of resources to address challenges that cannot be solved by single cities or departments (Chronéer et al., 2019; Dezuanni et al., 2018; Eskelinen et al., 2015; McCormick and Hartmann, 2017).

The living lab methodology goes back to experiments with open innovation for technological development at MIT in the late 1990s (Chesbrough, 2006; Ruijsink and Smith, 2016). In the European context, its roots can be traced back to the Scandinavian participatory design from the 1960s, European social experiments with information technologies in the 1980s, and various digital city initiatives from the 1990s (ENoLL, 2016; Ruiisink and Smith, 2016: 5-7). Current smart city initiatives similarly use living labs to enable spaces wherein corporate and public actors get together to develop and launch new technologies. Dubbed as the 'quadruple helix model of innovation' (Carayannis and Campbell, 2009), living labs prioritize the identification of user needs, knowledge, and competences of multiple stakeholders in technology design, where 'the fulfillment of societal functions becomes central' (Geels, 2004: 898, emphasis 
added). This collaborative approach to smartness responds especially to the divergent needs of cities in the EU, where fragmented regulatory and legislative national frameworks were for a long time perceived as obstacles to global competitiveness (European Commission Directorate-General for Enterprise, 2003).

The living lab approach was initially envisioned as an enhanced, userfocused test bed for new technologies in real-live settings. In the European context, living labs have now become established as spaces and methods of civic innovation and experimentation with future technologies that seek to enhance both user acceptance and competitiveness of European industries. A number of policy and funding initiatives in the EU since the early 2000s have placed great emphasis on the concurrent development of technologies and their functions within societal challenges associated with digitization, knowledge dissemination, and the design of public services.

One of the early examples in the domain of smart cities was the Intelcities project (2002-2003) that brought together dozens of cities, ICT companies, and research groups to prototype urban platforms and information systems (Curwell et al., 2005). In addition to the overall goal of achieving a 'sustainable society in smart cities' (European Commission Directorate-General, 2003: 188), the initiative recognized the challenges of digitization, social inclusion, and capacity building in local environments. The roadmap developed in the Intelcities project focused on the 'Knowledge Society' and 'Sustainable Urban Development' as long-term goals of EU policy. It also addressed how technological issues were linked and 
shaped by anticipated uses and users, trust, and confidence to achieve sustainability (Curwell and Cooper, 2010; Curwell et al., 2005). While the proliferation of living labs across European localities was eclectic and dispersed, initiatives in this domain explicitly advocated 'multidisciplinary and multicontextual research' in the design of digital technologies (Leminen et al., 2017), including collaborations among different sectors and recognizing the need for reskilling large segments of the population (European Commission Directorate-General, 2003).

In 2006, the institutionalization of the European Network of Living Labs (ENoLL) under the Finnish EU Presidency marked a culmination point of various policy, research and development milestones around the transformative role of ICTs in all domains of society since the 1980s (Ruijsink and Smith, 2016a, 2016b: 14-16). The European policy initiative 'i2010' solidified the living lab approach as the guiding principle for developing and implementing new technologies and set to establish a network of living labs across the continent to 'support the provision of services for broadly-based innovation deployment to industry, bringing technology test beds into real-life user environments' (Office for the Official Publications of the European Communities, 2006: 13). Combining open innovation principles with the tradition of Scandinavian participatory design (Ehn, 2018), the living labs set out to investigate changing relations between work, technologies, and skills in information-based and increasingly digital work environments. They aimed to bring together academics with unions, workers, and employers while 'striving to redefine democracy as much as they 
are about redefining design practices and relations in design' (Gregory, 2003: 71). Living labs thus endeavored to achieve more than test beds for new technologies; they offered ways to engage citizens in co-creating public infrastructures, applications, and new forms of governance (Brynskov et al., 2018 ; Mulder, 2012).

A few contemporary examples of how European cities implement smartness demonstrate the persistence of such living lab practices and civic innovation. The 'Digital Agenda Vienna' has defined nine principles of developing the city for citizens, administration and businesses alike, of which six principles are directly oriented to civic issues such as (gender) equality, participation, inclusion, and transparency (Stadt Wien, 2015: 6-9).

Similarly, the German city of Darmstadt has only recently become a model city for digital innovation, building on a broad alliance of local research institutions and businesses while receiving funding from the German Association of ICT Corporations (BITKOM) and the state of Hesse. Many action fields in Darmstadt's strategy are concerned with finding solutions in technological domains such as waste, energy, and traffic management, but another important goal is to develop citizen services that are 'easy, accessible and [that] strengthen the cohesion of the citizens of Darmstadt' (Digitalstadt Darmstadt, 2018: 10, own translation). The city aims for a 'digital cultural change' through winning trust and acceptance, fostering curiosity, rapid prototyping, and the avoidance of 'thinking in silos' (Digitalstadt Darmstadt, 2018: 32-33, own translation). 
Another example is Amsterdam, where the digitization of city services, business development, and citizen participation are based on principles of cocreation, open data, and citywide outreach and communication efforts. Through an institution like the DataLab Amsterdam, design approaches such as rapid prototyping and co-creation are used to develop solutions that can benefit local administrators and the ecosystem of citizens, businesses and civil society to mature into scalable solutions (Mora and Bolici, 2017; Zygiaris, 2013).

These cities differ widely in their ability to muster both visions and resources to become responsive to citizen demands for transparency and sustainability through locally divergent interpretations of smartness. Their attempts to align smartness with civic innovation underline that the development of new services and technologies need to co-evolve with public engagement. This requires developing and sustaining new networks of collaboration across domains to find models of urban governance that are adaptive to increased datafication (Claudel, 2018).

Motivated by the living lab approach, many European localities draw on smartness not just for implementing new technologies, but also taking stock of their own resources and aspirations, and creating partnerships among businesses, civic organizations, local governments, and universities. A living lab approach to smartness thus fosters a rather soft, horizontal innovation in social relations, knowledge sharing practices and modes of governance by shifting both the perceptions (among different stakeholders) and the centrality of technological solutions. An evaluation of Living Lab approaches among 
members of ENoLL finds that the highly context-specific identification of needs, the mobilization of 'tacit knowledge' of actors, and the governance within public-private partnerships all contribute to enhancing the legitimacy of this approach to innovation (Alam and Porras, 2018; Almirall et al., 2012; cf. Bifulco et al., 2017).

The rollout of living labs was rather organic across European localities, but policy frameworks and public funding provided by the EU since the early 2000s played a key role in establishing civic innovation as the guiding principle for technology development. While smartness may have emerged as an ostensibly universal framing of how cities take up digital infrastructures in recent years, European municipalities were already well versed in - and incentivized to - establishing new kinds of 'democratic ecologies' (Araya, 2015; cf. Burdett, 2013) among government, citizens, businesses, and society at large in technology design and implementation. The uptake of smartness as civic innovation and living labs in Europe, in contrast to entrepreneurialism in the United States, brings to the fore the central role of combining public investment, policy objectives, and governance structures in shaping the conditions in which smartness matures from a vision into reality.

Due to the highly context-specific identification of needs and aspiration and the long-term strategic goals of cities (if they are defined), cities can assume very different roles when it comes to using living lab approaches to put smartness to work. These can range from the city level of acting as providers of improved services to being catalysts for business development and regional 
growth. Or cities may position themselves on the neighborhood level to either foster local resources and networks or support rapid experimentation to develop and test new solutions in local settings with an eye toward scalable services (Leminen, et al., 2017: 26-28; cf. von Wirth et al., 2018). Unlike the corporate visions, where cities and tech companies struggle over the potentials and limits of smartness in a competitive and often ad hoc manner, living lab approaches afford municipalities, small and large, with a collaborative effort toward innovation, one that serves multiple stakeholder demands co-creatively. At least in the European context, such methodologies also open up new kinds of funding streams from EU-wide programs while establishing cross-sector partnerships between and inside cities.

\section{Discussion and Conclusion}

While comparing and contrasting visions of the smart city over the last decade in a Euro-Atlantic context, we heed Fred Turner's reminder that, 'As powerful as bits and algorithms are, and as dramatically as new media technologies call for new theories...., new media technologies retain a material dimension' (Turner, 2014: 257). The material dimension we find in the visions of smartness has two legs: first, it refers to the political and economic apparatuses that prompt the development of media technologies, and second, it is about the physicality of the urban environment that uses smartness to transform itself. Over the last decade, the smart city has gone from a corporate buzzword to an all-encompassing techno-utopian vision for urbanism in the 21st century to a rather cautious 
descriptor of what municipalities attempt to accomplish with digital technologies. Anticipatory visions undergirding the smart city may simply be a marketing strategy on the part of tech companies, or a totalizing promise by Silicon Valley that does not quite understand the politics of the city. Our analysis took a different turn and examined the variety of ways these visions are mobilized and altered by tech companies as well as municipalities.

We showed that the visions of smartness shifted, even in corporate promotions, when the political-economic landscape of cities transformed drastically following the financial crisis in 2008. Instead of focusing on climate change or sustainability, tech companies reorganized smartness as a viable way to foster economic growth and experimentation in places that were already hit hard by austerity. By attempting to bring the logics and techniques of digital platforms into the city, municipalities and tech companies used smartness hoping to revitalize urban infrastructures. European cities may downplay or even consciously avoid the term smart these days, but the living lab approach similarly has taken up the toolkit of smartness to grapple with complex urban problems. Rather than substituting an old technology (e.g. street lights) with a new one (e.g. networked, sensor-equipped LEDs), the core of living labs as spaces and methodologies is to create environments for collective problemsolving that addresses conflicting demands of inclusion, equality, accessibility and innovation around technological questions. 
The comparative approach (over time as well as spaces) presented here, highlights that different interpretations of smartness also depend on local political cultures, the availability of funding structures (venture capital vs. public funding), as well as historically shaped conceptions of entrepreneurship and civic engagement. Yet, as many cities deal with similar problems, taking visions of smartness as mere corporate hype misses an important point. Most cities in the early 21 st century try to come to terms with both the demands of citizens and the technological solutionism aggressively promoted by tech corporations. They try to address novel challenges that require new domains of expertise and lack the necessary capital and labor for meaningful interventions. These taxing conditions do not justify the insufficient public accountability and rapid privatization of local governance in any smart city-in-progress. But they may explain the ongoing appeal of smartness and why legions of public officials, and even residents, are enamored with the idea - even when they are careful not to use the term itself. Analyzing what smartness does, instead of solely examining its discourses, prompts further studies that investigate the practical, immediate, not to mention strategic, uses of smart city visions in localities. 